\title{
SUTURA CON SEDA EN LA OPERACION CESAREA
}

\author{
Doctores Jorge Milanés y Alberto Zabaleta Lombana*
}

El catgut como material de sutura ha gozado tradicionalmente del favor del cuerpo médico, y no obstante cualquier pequeño inconveniente que pudiera atribuírsele, es elemento indispensable en el arsenal de toda sala de cirugía.

$\mathrm{Su}$ preeminencia es tanta que se prodiga en toda clase de sutura, y en relación a la cesárea hay cirujanos que cierran la incisión uterina con un surcete doble de puntos cruzados de catgut crómico. Nada, pues, habría que agregar a su haber.

La reparación de la herida uterina en la cesárea se comenzó a practicar rutinariamente a partir del año 1882, gracias a los trabajos de los ginecólogos alemanes Ferdinand Adolph Kehrer y $M_{a ̈ x}$ Sanger, quienes laborando independientemente concordaron en este punto hoy fundamental, con el fin de aislar de modo seguro y duradero la cavidad uterina y sus secreciones de la serosa peritonea!. Para tal objeto, Kehrer recomendaba una doble sutura con seda fenicada: la primera muscular y serosa la segunda.

* Facultad de Medicina. Universidad de
Es de tener en cuenta que antes de estos autores y durante tres siglos, salvo contadas excepciones, la matriz era introducida sin sutura en la cavidad abdominal después de la operación cesárea, primando el concepto que su sola contractilidad era suficiente para verificar la hemostasis, viéndose trastornada aquélla si se efectuaba la sutura del músculo.

En nuestro medio, reemplazada por el catgut, ha caído la seda desde hace tiempo prácticamente en desuso, acusada como factor de morbilidad postoperatoria. No obstante esta animadversión, tal vez fundada en el descuido de pequeños detalles de asepsia, hemos venido usando la seda rutinariamente en todas nuestras intervenciones, excepto en las laparotomías de casos infectados; en las mucosas y en el cierre de la cúpula vaginal en las histerectomías, con resultados tan satisfactorios que honradamente nos permitimos recomendar su uso.

Podríamos anotar como condiciones favorables de la seda, aparte el reducidísimo costo comercial, su resistencia

Cartagena. 
que permite nudos bien ajustados; siempre más firmes por menor superficie de fricción mientras más delgada es la hebra. Además de su facilidad de esterilización, la seda no irrita los tejidos ni sufre el fenómeno de la imbibición, que puede determinar el aflojamiento de los puntos de sutura.

Considerada como material inabsorvible, más bien debe catalogarse como de absorción lenta, que alcanzaría en los tejidos una duración hasta de dos años según algunos autores; siendo paulatinamente reemplazada por fibrosis. En dos pacientes reintervenidas una a los seis meses por embarazo ectópico y otra a los dos años para nueva cesárea por desproporción céfalo-pélvica, encontramos en la aponeurosis pequeños restos de seda.

Su principal inconveniente lo sería la tendencia a entretener la supuración en casos de infección de la herida, actuando como cuerpo extraño. Los antibióti$\cos$ no surten aquí efecto alguno, imponiéndose la inmediata remoción del hilo.

\section{MATERIAL Y METODO}

Queremos referirnos especialmente a una técnica simplificada y notablemente económica para el tratamiento de la histerotomía en la operación cesárea segmentaria que viene siendo practicada por uno de nosotros. (Doctor Jorge Milanés, durante 10 años, con resultados que nos permiten garantizar su uso).

En el cierre de todos los planos de la laparotomía utilizamos el hilo crochet mercerizado, fabricado en Cali por la industria colombiana de hilos La Garantía de A. Dishington S. A. Se vende en el comercio en distintos diámetros, en bolas de 20 gramos de peso y 500 yardas de longitud. Cortada en hebras más o menos largas, es enrollada en pequeños tubos de cristal y esterilizada al autoclave durante 15 minutos a 12 libras de presión, quedando así lista para ser usada en cirugía.

Con tal material, seda números 80 y 60 , hacemos la sutura según la técnica siguiente:

Utero: Una sola costura a puntos cruzados, interrumpida. Distancia aproximada de $1 \mathrm{cmt}$. entre uno y otro punto con seda número 80 .

Los bordes se afrontan exactamente, interesando todo el espesor de la capa muscular a la menor distancia posible de la herida, evitando incluír la mucosa.

La tensión del nudo está dada por la resistencia de la seda, la cual nunca es lo suficiente como para impedir el riego sanguíneo de la región, pues como es natural, a poco de excederla, se rompe el hilo, lo cual es muy frecuente para quien no tiene la suficiente práctica con este material. Beneficio que no podemos menos que hacer notar ya que con elementos de mayor resistencia, el cirujano en ocasiones estrangula, por así decirlo, los haces musculares determinando una disminución de su vitalidad y potencialmente una cicatrización defectuosa.

Peritoneo vésico-uterino. Indistintamente puntos simples separados o sutura continua con seda número 80 .

Peritoneo parietal. Sutura continua con hilo doble de seda número 80 . 
Aponeurosis. Sutura entrecortada de puntos cruzados. Seda número 60.

Tejido celular subcutáneo. Puntos separados sencillos. Seda número 80 .

Ligaduras de vasos. Seda número 80.

Concedemos importancia al corte de los cabos de hilo exigiéndole al ayudante que lo practique al ras a fin de evitar sobrantes inoficiosos. En relación con la sutura a puntos separados del útero, recalcamos que es una sola costura que impone apenas el adosamiento simétrico de los bordes de la herida, considerando que la mínima cantidad de hilo utilizada imposibilita reacciones por la presencia del cuerpo extraño como pudiera provocarla el exceso de catgut en la práctica de más de una sutura con este material. J. P. Greenhill, en el comentario al trabajo de Potter y Johnston sobre el uso de la seda en cesáreas, relata dos casos de expulsión por vía vaginal de sendas suturas uterinas de catgut.

En cuanto a la cicatriz uterina, factor este de máximo interés en el porvenir de las mujeres cesareadas en el transcurrir de un posterior embarazo y trabajo de parto, para que sea lo más perfecta posible, debe respetarse y repararse convenientemente la integridad anatómica de la región, no violentando los tejidos y evitando menoscabar su nutrición mediante suturas y nudos cuya opresión hace palidecer el músculo uterino al impedir el necesario aflujo sanguíneo.

En los cuidados postoperatorios de la herida abdominal es necesario, en primer lugar, la correcta aposición de sus labios por nudos que no constriñan la piel. Hacemos su limpieza con alcohol y seguidamente se cubre con una sola lámina de gasa sostenida por tres tirillas de esparadrapo y empapada nuevamente con alcohol. No útilizamos apósitos de gasa como tampoco fajas de esparadrapo que conjuntamente contribuyen a impedir la debida transpiración de la zona vecina de la herida. La gasa es renovada diariamente y cada vez humedecida con alcohol, único líquido que usamos durante la curación. En ocasiones practicamos el corte precoz de punto a las 48 horas.

\section{MATERIAL}

Presentamos en este trabajo $114 \mathrm{ca}$ sos de intervención cesárea segmentaria transperitoneal en los que hemos utilizado la seda como material de sutura, según la técnica anotada anteriormente.

Esta pequeña estadística ha sido tomada del registro de cirugía de la Maternidad "Rafael Calvo C.", desde el 2 de abril de 1958 hasta el 7 de mayo de 1962, tiempo durante el cual se llevaron a cabo 1.026 operaciones de distinta naturaleza.

Las cesáreas objeto de este estudio fueron practicadas 87 en pacientes civiles, y 27 en pensionadas; casi siempre las primeras bajo la sospecha de casos impuros por estar la clínica dedicada a la enseñanza universitaria.

En algunos de estos casos se dejó la terramicina de tipo endovenoso en solución en la cavidad abdominal o se usaron lus antibióticos requeridos en el post-operatorio y las demás medidas terapéuticas necesarias. 
La edad de estas pacientes varió en amplios límites siendo la menor de 16 años (presentación de frente) y la mayor de 44 (sufrimiento fetal por inercia uterina secundaria). En cuanto a la causa de la intervención, podemos decir que casi siempre el motivo considerado principal estuvo asociado a otros facto- res, algunos de ellos por sí solos capaces de condicionar la misma conducta.

Aunque escapa un tanto a la materia de este artículo, nos permitimos presentar en dos cuadros sinópticos la causa que determinó la cesárea (indicación principal y secundaria) y la clase de anestesia usada.

CUADRO No 1

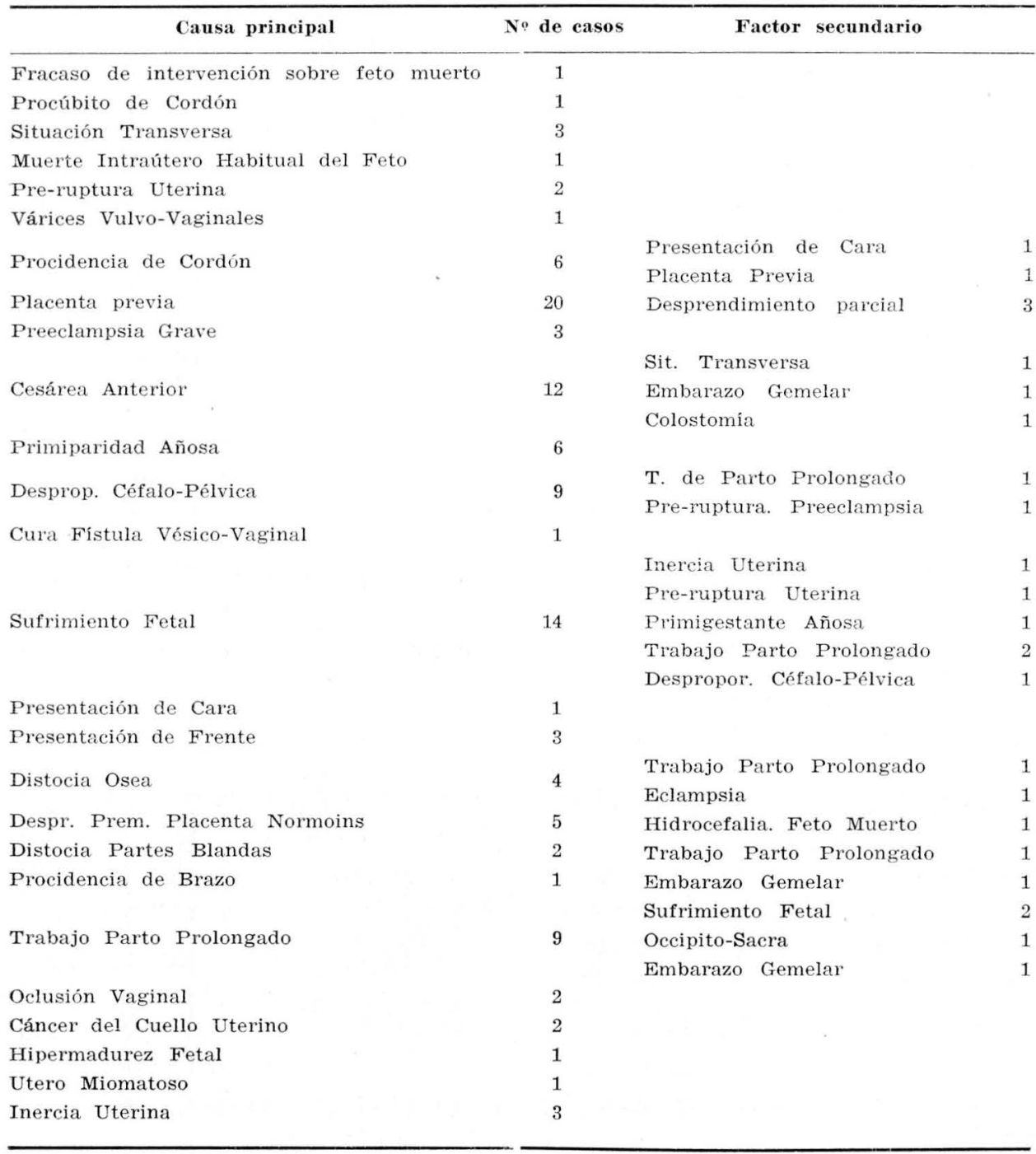


CUADRO No 2

\begin{tabular}{|c|c|c|c|c|c|c|c|c|}
\hline Anestesia & Anestésicos & Usados & & & & & Total de & casos \\
\hline Local & Xilocaína $1 \%$ & 9 & & & & & & 9 \\
\hline $\begin{array}{l}\text { Peridural } \\
\text { Continua }\end{array}$ & Xilocaína $1 \%$ & 24 & & & & & & 24 \\
\hline $\begin{array}{l}\text { Raquídea } \\
\text { General }\end{array}$ & $\begin{array}{l}\text { Pantocaína } \\
\text { Pentotal- }\end{array}$ & 10 & $\begin{array}{l}\text { Scurocaína } \\
\text { Xilocaína }\end{array}$ & 45 & Xilo- & & Trilene & 55 \\
\hline & Eter. & 10 & Pentotal & 3 & $\begin{array}{l}\text { Pentot. } \\
\text { Eter }\end{array}$ & 3 & 10 & 26 \\
\hline
\end{tabular}

\section{MORBILIDAD}

Realmente tenemos por qué estar agradecidos de la técnica operatoria y de los cuidados que dispensamos a la herida quirúrgica. En nuestros casos no hemos lamentado hasta el presente ninguna dehiscencia siquiera parcial de la cicatriz, no obstante las malas condiciones generales de nutrición de algunas pacientes.

Una de ellas, de 34 años y 1.40 cmts. de talla, de pelvis uniformemente estrecha y cuyos tres embarazos habían terminado por cesárea, pesaba solamente 29.5 klgs. Padecía además, una dermatitis generalizada desde los tres últimos meses de gestación a consecuencia de la aplicación de una vacuna. Presentó infección de los tres últimos puntos de la herida, interesándose el tejido celular a ese nivel y curando después de la extracción de los hilos.

Como ésta, otras pacientes en escaso número, entre ellas la afecta de colostomía, hicieron supuración localizada de uno o dos puntos de piel y grasa, siempre los más inferiores de la herida a nivel de pliegue abdomino-genital y sin que dicha ocurrencia interfiriera con su estado general o alterara en forma notoria el curso del postoperatorio.

Muchas de nuestras pacientes tanto de clientela hospitalaria como privada han sobrellevado en buenas condiciones su cicatriz uterina en embarazos subsiguientes, en trabajos de prueba y en partos sin haber sufrido ruptura o menoscabo de la misma.

\section{SUMARIO}

Presentamos una pequeña serie de 114 casos observados durante 4 años en la Clínica de Maternidad, Rafael Calvo C. como parte de una más dilatada experiencia sobre la sutura en cesáreas con hilo de seda.

Se explican las características y ventajas de este hilo y las modalidades técnicas de la sutura en cada plano, recomendando, especialmente en cuanto al músculo uterino, nuestro sistema de una sola costura a puntos separados.

Llamamos la atención sobre los curdados postoperatorios de la herida quirúrgica.

Adicionamos el presente trabajo conx dos cuadros relativos a las causas de 
intervención y algunas características de la anestesia utilizada.

\section{CONCLUSIONES}

1o La seda es un material de bajísimo costo comercial, de fácil esterilización y de altísima eficacia como elemento de sutura.

$2^{\circ}$ No irrita los tejidos ni sufre en ellos el fenómeno de la imbibición.

$3^{\circ}$ No provoca, o escasamente lo hace, reacciones como sustancia extraña al no usarse más que una pequeña cantidad de la misma.
4⿳⺈ Su escasa resistencia y mínimo espesor impide la violencia y constricción sobre los tejidos a suturar, lo que junto a las condiciones anotadas anteriormente $\left(2^{\circ}\right.$ y $\left.3^{\circ}\right)$ facilita un mejor riego sanguíneo acompañando un proceso de cicatrización más fisiológico en el cual habría una menor formación de tejido conectivo cicatricial.

50 La reparación de la histerotomía con una sola hilera de puntos separados da mayor rapidez y consiguiente economía de tiempo.

69 La seda en el músculo uterino garantiza tanta, o mayor seguridad, para el porvenir de las cesareadas en posteriores embarazos, como el catgut.

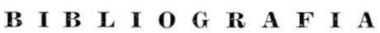

1. POTTER M. and JOHNSTON, D. C.: Uterine Closure in Cesarean Section. Am. J. Obst. and Gyn. Vol. 6, No 4. 760. 1954

2. Acta Ciba: Jul.-Sept. 107. 1952

3. TORRAdo NUÑez L.: Operación Cesárea. Rev. Col. Obst. Gin. Vol. XII. 383. 1961.

4. MUÑOZ DELGAdo S., COBO COBO E.: Indicaciones Selectivas de la Cesárea Seg. Longitudinal. Rev. Col. Obs. Gyn. Vol. XI. 359. 1960.

5. SPIVACK J. L.: Téenica Quirúrgica en las Operaciones Abdominales. Edit. HispanoAmericana. Pág. 5. México. D. F. 1937.

6. ROB. CH. and SMITH R. Operative Surgery. Vol. I, pág. 5. F. A. Davis Co. Philadelphia U. S. A. 1956.

7. GReenhill J. P. Principios y Práctica de Obstetricia de Delee. Vol. II. 1.210. Unión Tip. Edit. Hispano-Americana 1955.

8. Zabaleta lombana A., milanes J. Terramicina en la Cavidad Abdominal. Rev. Col. Obst. Gin. Vol. XII. 556. 1961. 